University of Nebraska - Lincoln

DigitalCommons@University of Nebraska - Lincoln

USDA National Wildlife Research Center - Staff Publications
U.S. Department of Agriculture: Animal and Plant Health Inspection Service

August 2006

\title{
Landscape Use and Movements of Wolves in Relation to Livestock in a Wildland-Agriculture Matrix
}

Andreas S. Chavez

Utah State University, Logan, chavez.102@osu.edu

Eric M. Gese

Utah State University, eric.gese@usu.edu

Follow this and additional works at: https://digitalcommons.unl.edu/icwdm_usdanwrc

Part of the Environmental Sciences Commons

Chavez, Andreas S. and Gese, Eric M., "Landscape Use and Movements of Wolves in Relation to Livestock in a Wildland-Agriculture Matrix" (2006). USDA National Wildlife Research Center - Staff Publications. 413.

https://digitalcommons.unl.edu/icwdm_usdanwrc/413

This Article is brought to you for free and open access by the U.S. Department of Agriculture: Animal and Plant Health Inspection Service at DigitalCommons@University of Nebraska - Lincoln. It has been accepted for inclusion in USDA National Wildlife Research Center - Staff Publications by an authorized administrator of DigitalCommons@University of Nebraska - Lincoln. 


\title{
Landscape Use and Movements of Wolves in Relation to Livestock in a Wildland-Agriculture Matrix
}

\author{
ANDREAS S. CHAVEZ, ${ }^{1}$ Department of Forest, Range, and Wildlife Sciences, Utah State University, Logan, UT 84322, USA \\ ERIC M. GESE, ${ }^{2}$ United States Department of Agriculture, Wildlife Services, National Wildlife Research Center, \\ Department of Forest, Range, and Wildlife Sciences, Utah State University, Logan, UT 84322, USA
}

\begin{abstract}
Wolves (Canis lupus) have expanded their distribution into areas of the midwest United States that have not had wolves for several decades. With recolonization of wolves into agricultural areas, there is increasing concern of wolf-livestock conflicts. To assess the risk wolves may pose to livestock, we initiated a 3-year study investigating the activity patterns, movements, habitat use, visitation to livestock pastures by wolves, and the occurrence of depredation events in an agricultural-wildland matrix in northwestern Minnesota, USA. From June 1997 to November 1999 , we captured 23 wolves, including pups, from 3 packs; we radiocollared 16 of these wolves. We tracked radioed wolves intensively on a $24-h o u r$ basis during the spring, summer, and autumn of 1998 and 1999. We found wolves passed directly through a pasture containing cattle on $28 \%$ of the nights of tracking; $58 \%$ and $95 \%$ of the wolf locations were $\leq 1 \mathrm{~km}$ and $\leq 5 \mathrm{~km}$ from a pasture, respectively. Space use of wolves showed that while they visited livestock pastures during the 24-hour tracking sessions, they apparently were passing through these pastures with cattle and not preying on livestock. When compared to random simulations of movements, wolves appeared to encounter livestock pastures randomly. Thirty percent of random movements passed directly through a pasture; $65 \%$ and $95 \%$ of random movements were within $\leq 1 \mathrm{~km}$ and $\leq 5 \mathrm{~km}$ of a pasture, respectively. Wolves were more active at night than during the day. Wolves avoided pastures during the day and visited pastures at night when depredations were most likely (i.e., human presence was low). Visitation of livestock pastures was not related to any discernible characteristics of the pastures (i.e., pasture size, cattle density, distance to human habitation, percent forest cover, index of deer abundance). However, pastures in which livestock were killed by wolves contained more cattle than pastures without depredations, but in 1998 only. While the risk of wolf predation on livestock was potentially high (wolves were within $\leq 1 \mathrm{~km}$ of a pasture on $58 \%$ of nights), few livestock were actually killed. During the 3-year study, only 8 animals (all young or vulnerable livestock) were depredated by wolves. Maintaining healthy wild prey populations, removing offending wolves that kill livestock, and encouraging effective and proper husbandry practices (e.g., disposal of carcasses) among livestock producers, should allow for the persistence of wolves in northwestern Minnesota, USA, while minimizing their impact to farmers in this agriculture-wildland matrix. (JOURNAL OF WILDLIFE MANAGEMENT 70(4):1079-1086; 2006)
\end{abstract}

\section{Key words}

Canis lupus, depredations, livestock, Minnesota, movements, risk, wolves.

Gray wolves (Canis lupus) evolved as effective predators of native ungulates in North America (Mech 1970). The colonization and settlement of North America by Europeans introduced domestic livestock into areas occupied by wolves. The subsequent threat wolves posed to livestock was one of the primary factors prompting widespread eradication campaigns against wolves by the new settlers (Young and Goldman 1944). As a result, wolf numbers dwindled across their range in the conterminous United States. By the mid-20th century the last substantial wolf population remaining in the United States outside of Alaska occurred in the vast wilderness areas of northeastern Minnesota (Mech 1966). The eastern timber wolf (C. l. lycaon), a subspecies of gray wolves inhabiting parts of eastern United States and southeastern Canada, was listed by the United States Fish and Wildlife Service as endangered in 1974 under the Endangered Species Act of 1973. In 1978, a Recovery Plan for the Eastern Timber Wolf was developed by the Eastern Timber Wolf Recovery Team (U.S. Fish and Wildlife Service 1978). One of the criteria for recovering the eastern timber wolf was to ensure the perpetuation of the wolf in various parts of its former range in Minnesota.

Wolf-livestock conflicts are an emotionally volatile issue in rural areas and may exacerbate the perceived risk by rural landowners

\footnotetext{
1 Present address: United States Fish and Wildlife Service, Carlsbad, CA 92009, USA

2 E-mail: egese@cc.usu.edu
}

that wolves pose to livestock. To accurately assess the risk wolves pose to livestock, it is necessary to provide scientific information on the relationship between wolves and livestock. However, very little is known about wolves living in areas with abundant livestock because most of the seminal studies on wolves in the Upper Midwest have occurred in vast forested areas with little to no livestock (e.g., Van Ballenberghe et al. 1975, Fritts and Mech 1981, Fuller 1989). In addition, since wolves are most likely to kill livestock at night, information regarding their nocturnal movements is one of the critical aspects needed for a better understanding of wolf-livestock relationships. However, wolf behavior during nighttime is also poorly understood because of the inability of prior studies to monitor wolves during nighttime due to their reliance on daytime aerial telemetry for monitoring wolves in vast forested areas (e.g., Mech and Karns 1977, Fritts and Mech 1981, Fuller 1989).

The expanding wolf range in northwest Minnesota, USA, provided us with an opportunity to investigate wolf behavior in a semi-agricultural area with abundant cattle. In addition, the ubiquity of roads and the openness of the habitat in the agricultural lands allowed us to study nocturnal wolf movements from the ground with a vehicle and radiotelemetry. We investigated landscape use, movements, activity patterns, and habitat use of wolves in relation to the occurrence of livestock depredation events in an agricultural area with cattle to better assess the risk wolves may pose to livestock in northwestern 

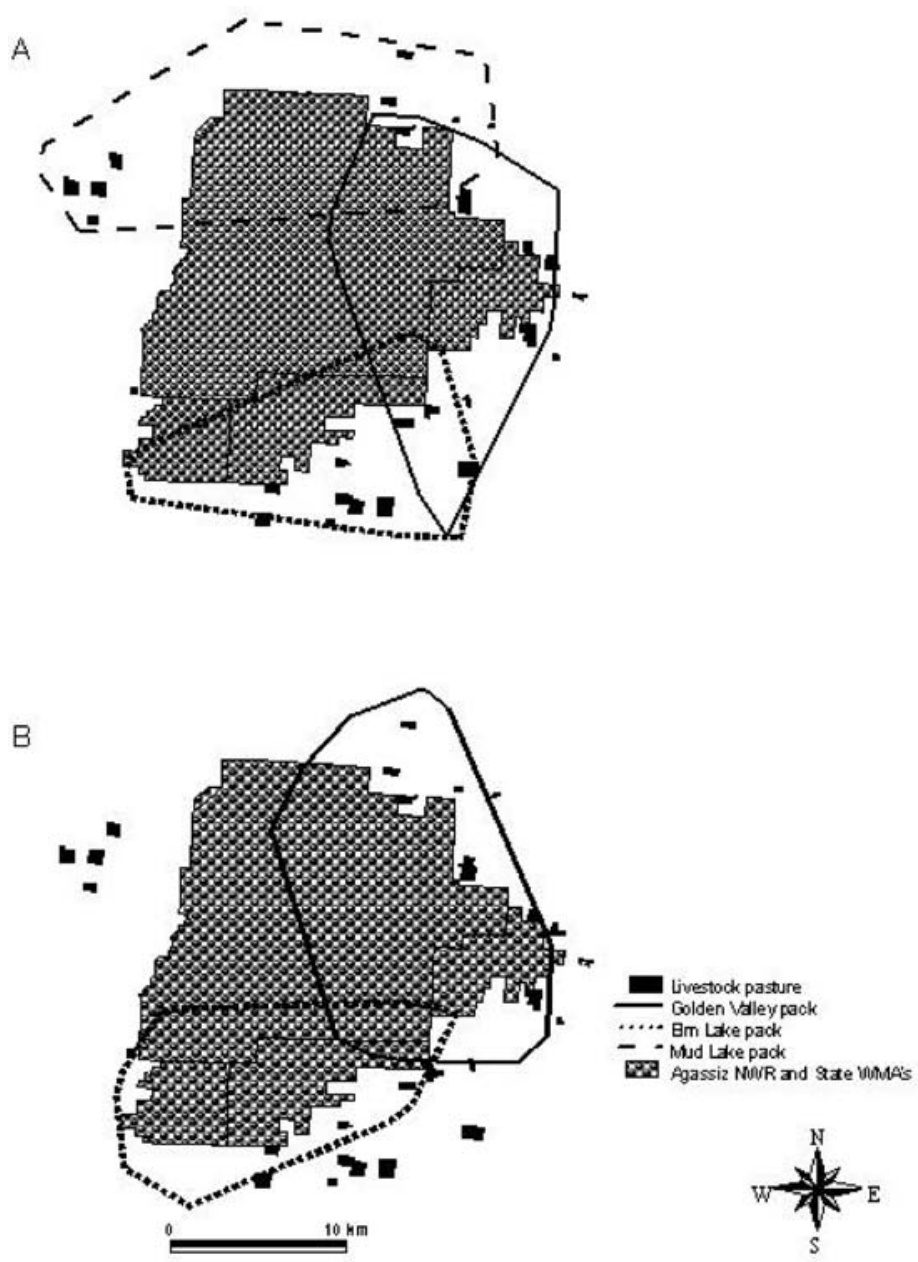

Figure 1. Locations of wolf packs monitored in (A) 1998 and (B) 1999, in relation to livestock pastures and Agassiz National Wildlife Refuge (NWR) and State Wildlife Management Areas (WMAs), northwestern Minnesota, USA.

Minnesota, USA. Specifically, we addressed whether wolves in an agricultural-wildland matrix are using the agricultural lands (mainly livestock pastures) in the surrounding area, when wolves visit these pastures, how frequently they visit pastures containing livestock, what other habitats they use besides livestock pastures, and whether wolves pose a risk to livestock when visiting these pastures compared to the actual frequency of depredation events.

\section{Study Area}

Our study area was located in the Red River Valley of northwest Minnesota, USA, in the northwest periphery of wolf range in the Great Lakes region (Berg and Benson 1999). The study area was within an ecotone region consisting of tallgrass prairie, aspen (Populus spp.) parkland, and boreal forest ecosystems. Rural development converted most of the native vegetation communities into agricultural lands during the past 2 centuries, leaving only remnants of forests, grasslands, and wetlands. The 1,200- $\mathrm{km}^{2}$ study area $\left(48^{\circ} 19^{\prime} \mathrm{N}, 95^{\circ} 59^{\prime} \mathrm{W}\right)$ was comprised of an island of natural habitat consisting of Agassiz National Wildlife Refuge and 3 adjoining State lands (Elm Lake, Eckvoll, and Mudlac Wildlife Management Areas) surrounded by agricultural lands. This created a hard boundary or interface between wildlands and agriculture lands. Public access was restricted on the Federal land but not on
State lands. The study area was comprised of $53 \%$ cultivated lands, $20 \%$ wetlands, $10 \%$ brushlands, $10 \%$ forests (deciduous and coniferous), and $7 \%$ pasture and grasslands. The regional climate was characterized by short warm summers and long cold winters. Snow cover was generally continuous from late November until April. Due to snow, livestock grazing in pastures generally occurred from May to early November. Moose (Alces alces), white-tailed deer (Odocoileus virginianus), beaver (Castor canadensis), muskrats (Ondatra zibethicus), and eastern cottontail rabbits (Sylvilagus floridanus) were the main native prey available to wolves.

Cattle were the predominant livestock species with approximately 1,985 head of cattle in 22 pastures $\leq 4.8 \mathrm{~km}$ from the border of the Refuge and contained within the territories of the 3 radioed wolf packs (Fig. 1). Livestock were present in these pastures throughout the grazing season. Other livestock consisted of sheep and pigs. One sheep producer lived within the study area and their sheep were mixed with cattle. There was also one pig farm in the area, but the animals were enclosed in a barn and not vulnerable to wolf predation. Cattle pastures ranged in size from 8.33-104.11 ha; mean of $39.77 \pm 28.57$ (SD) ha. The number of cattle in the pastures ranged from 20-300 head; mean of 90.2 head. In addition, the amount of open habitat in pastures ranged between $64 \%$ and $100 \%$; mean of $87 \pm 10 \%$. The average distance of the center of each pasture to the closest human dwellings was $0.53 \mathrm{~km} \pm 0.45$ (range: $0.11-2.17 \mathrm{~km}$ ).

\section{Methods}

\section{Capture, Marking, and Monitoring of Wolves}

We trapped wolves with steel foothold traps (Kuehn et al. 1986) with attached trap-tranquilizer devices to reduce injury (Sahr and Knowlton 2000). Our trapping efforts took place on and around Agassiz in areas indicating high wolf activity based upon tracks, howling, and rendezvous sites. We also net-gunned wolves from a helicopter (Barrett et al. 1982) during winter. We anesthetized all captured wolves with tiletamine and zolazepam following Kreeger (1996). Each wolf was weighed, measured, ear-tagged, aged by tooth wear, examined for ectoparasites and physical condition, blood sampled, and fitted with a very high-frequency mortalitysensing radiocollar (Telonics, Inc., Mesa, Arizona, or Advanced Telemetry Systems, Inc., Isanti, Minnesota). We only radiocollared individuals weighing $>12 \mathrm{~kg}$. All capture and handling procedures were approved by the Institutional Animal Care and Use Committee at Utah State University (IACUC approval no. 879).

We used a 4-element null-peak antenna system that was vehiclemounted for radiotracking collared wolves. Mean telemetry error of the null-peak system was $\pm 3.4^{\circ}$ based upon reference transmitters. During the spring, summer, and autumn of 1998 and 1999, we tracked each radioed wolf for a 24 -hour period at least once a week with sequential locations obtained at 45-minute intervals. For each 24-hour tracking session, we systematically chose a focal individual to monitor and then alternated tracking sessions among the collared wolves. We estimated telemetry locations from triangulations of $\geq 3$ azimuths with an angle between $20^{\circ}$ and $160^{\circ}$ (White and Garrott 1990). We entered azimuths and radiotracking positions into the software package LOCATE II (Pacer, Inc., Truro, Nova Scotia, Canada), which 
estimated Universal Transverse Mercator locations for each triangulation with an associated $95 \%$ error area. We entered all locations into ArcView (Environmental Systems Research Institute, Inc., Redlands, California) for further analysis.

\section{Home Range, Daily Activity, and Habitat-Use Patterns}

Estimating animal home-range size can vary due to either sampling strategy (Gese et al. 1990) or home-range estimator. We estimated home-range size with the minimum convex polygon method (MCP; Mohr 1947, Southwood 1966) to allow comparisons with estimates of wolf home-range size from prior wolf studies in the upper Midwest.

We compared wolf movement rates at 4 time periods of the day to investigate wolf daily activity patterns. We used differences in daily movement rates $(\mathrm{km} / \mathrm{hr})$ and not changes in radio-signal attenuation for assigning activity because the latter was either too unreliable, variable, or subject to observer bias. We classed the 4 time periods of the day as: dawn $(1 \mathrm{hr}$ before to $2 \mathrm{hrs}$ after sunrise), day ( $2 \mathrm{hrs}$ after sunrise to $1 \mathrm{hr}$ before sunset), dusk ( $1 \mathrm{hr}$ before to $2 \mathrm{hrs}$ after sunset), and night ( $2 \mathrm{hrs}$ after sunset to $1 \mathrm{hr}$ before sunrise). We determined sunset and sunrise times for each 24-hour tracking session (Astronomical Applications Department, U.S. Naval Observatory, Washington, D.C.). We calculated movement rates as the distance divided by the time between successive locations, and we then averaged them for each activity period for each 24-hour tracking session for each wolf. We used a Kruskal-Wallis test $(H)$ to examine differences in movement rates among the 4 time periods. If the null hypothesis was rejected, we used a nonparametric multiple-comparison Nemenyi test with equal sample sizes to determine which time periods were statistically different from each other (Zar 1996).

The assignment of wolf locations to various habitat types was performed in ArcView using a vector-based digital map from the Minnesota Department of Natural Resources (MDNR) Land Use-Land Cover map $(30 \times 30-\mathrm{m}$ grid $)$. We consolidated the MDNR's map into 3 general habitat classifications: open habitat (urban and rural development, cultivated land, hay-pasturegrassland, and mining), semi-open habitat (brushland, water, and bog-marshland), and closed habitat (hardwood and conifer forests). We eliminated all telemetry locations from the analysis with an associated $95 \%$ error area that was greater than the area of the habitat polygon for which that location was attributed. We eliminated few telemetry locations because $95 \%$ error areas were generally much smaller than the habitat patch areas. The mean area of the $95 \%$ error polygons was $0.11 \mathrm{~km}^{2} \pm 0.88 \mathrm{SD}$, while the mean patch size of the habitats was $18.67 \mathrm{~km}^{2} \pm$ 5.92. We determined habitat availability by calculating a $100 \%$ MCP home range (Mohr 1947) for each pack and then summing the amount of each habitat type within the home range. We estimated $\mathrm{MCP}$ home ranges with the ArcView Animal Movement Analysis Extension (Hooge and Eichenlaub 1997).

We used a Friedman $(F)$ nonparametric-rank test to examine the wolves' habitat selection patterns (Alldredge and Ratti 1992). The Friedman test is a nonparametric analysis of variance based on ranks of a randomized block design. We used the Friedman method to compute the ranked sum differences between usage and availability of the different habitat types. We used the individuals and habitat types as the blocks and treatments, respectively. We tested the null hypothesis that the rank of differences between use and availability was not different among habitat types. If the null hypothesis was rejected, we measured the statistical differences between use of different habitats with a multiple comparisons analysis (Conover 1999). We regarded any 2 habitats with ranks separated by more than the multiple comparison $F$ test value $\left(T_{2}\right)$ as unequal with a statistically significant habitat preference belonging to the habitat with the higher rank. We performed Friedman tests for all time periods of the day combined, daytime only, and nighttime only. We ranked habitat selection on a relative scale from least selected for to most selected for.

When analyzing data for habitat selection studies, there are 2 areas of caution regarding temporal autocorrelation and independence of sample units assumptions (Swihart and Slade 1985, Alldredge and Ratti 1986). Our study did not violate temporal autocorrelation assumptions because we acquired a systematic sample of movement trajectories on the landscape for each wolf pack (see Otis and White 1999 for further discussion). In addition, we avoided violating independence of sample unit assumptions by pooling the locations from individual wolves within the same pack and using the pack as the sample unit.

\section{Visitation Rates into Pastures}

To examine wolf visitation rates into cattle pastures, we determined the distance between a wolf's location and the nearest pasture during each 24-hour tracking session; a distance of zero meant the wolf passed through the pasture. We then compared their visitation rates into pastures from real movements with visitation rates based on simulated random-directional movements. We also determined the frequency of distances from a livestock pasture based upon the observed wolf movements and the simulated random movements. Bell (1991) listed 4 variables that can be used for simulating movements by organisms: 1) reactive distance (at which an animal detects a resource), 2) the length over which the simulated animal does not change direction, 3) turn angle concentration or directionality, 4) and changes in locomotory patterns over time. For the simulated random-directional movement models, we randomized the directionality (turn angle) at each sequential location and kept the same starting locations and distances moved between successive locations from the real wolf movement data. We simulated the random-directional movements 100 times for each 24-hour tracking session with an ArcView Random Path extension (P. Terletzky, Utah Army National Guard, Utah State University, unpublished program) and determined the frequency of distances from the nearest pasture (or if it passed through the pasture). We used a $\chi^{2}$-goodness-of-fit test to determine if the frequency of distances between the observed and the random datasets were different. If the visitation rates based on the observed data were greater than the random data then we presumed the wolves were attracted to the pastures. If the observed data were less than expected, then we presumed wolves were avoiding pastures, and if they were the same, we presumed wolves were indifferent to pastures and visited them randomly.

We also examined wolf visitation rates to pastures during different times of the day and seasons using a Kruskal-Wallis test (H) and nonparametric multiple-comparison Nemenyi test. Time periods for this analysis followed the same periods that we used in 
Table 1. Proportion of habitat used versus available for day and night locations for individually radioed wolf packs in 3 habitat types, northwestern Minnesota, USA, 1998-1999.

\begin{tabular}{|c|c|c|c|c|c|c|}
\hline \multirow[b]{2}{*}{ Time } & \multirow[b]{2}{*}{$\begin{array}{c}\text { Pack } \\
\text { no. }\end{array}$} & \multicolumn{3}{|c|}{ Habitat type } & \multirow{2}{*}{$\begin{array}{c}\text { Friedman } \\
\text { statistic } \\
(F)\end{array}$} & \multirow{2}{*}{$\begin{array}{c}\text { Multiple } \\
\text { comparison } \\
\left(T_{2}\right)\end{array}$} \\
\hline & & Open & $\begin{array}{l}\text { Semi- } \\
\text { open }\end{array}$ & Closed & & \\
\hline \multicolumn{7}{|l|}{$\%$ Habitat use } \\
\hline Day & 1 & 0.454 & 0.383 & 0.163 & & \\
\hline Day & 2 & 0.149 & 0.711 & 0.141 & & \\
\hline Day & 3 & 0.328 & 0.509 & 0.163 & & \\
\hline Sum of ranks & & 3 & $8^{a}$ & $7^{\mathrm{a}}$ & $7.00^{b}$ & 3.93 \\
\hline \multicolumn{7}{|l|}{$\%$ Habitat use } \\
\hline Night & 1 & 0.828 & 0.108 & 0.064 & & \\
\hline Night & 2 & 0.302 & 0.513 & 0.153 & & \\
\hline Night & 3 & 0.573 & 0.310 & 0.117 & & \\
\hline Sum of ranks & & $8^{a}$ & 3 & $7^{\mathrm{a}}$ & $7.00^{b}$ & 3.93 \\
\hline \multicolumn{7}{|c|}{$\%$ Habitat available } \\
\hline Day-night & 1 & 0.520 & 0.364 & 0.116 & & \\
\hline Day-night & 2 & 0.302 & 0.579 & 0.119 & & \\
\hline Day-night & 3 & 0.441 & 0.442 & 0.117 & & \\
\hline
\end{tabular}

${ }^{\text {a }}$ Sum of ranks for each time period with the same letter represents no statistical difference.

${ }^{\mathrm{b}} P<0.05$ for Friedman statistic.

our analysis on daily activity patterns. We based seasons on wolf biological seasons during nonwinter months: denning (15 Apr-30 Jun), rendezvous (1 Jul-30 Sep), and postrendezvous (1 Oct-15 Nov).

To investigate whether certain pasture characteristics influenced wolf visitation, we performed a Student's $t$-test to test differences between pastures that were and were not visited. Livestock were present in these pastures throughout the grazing season. We examined 5 pasture characteristics (number of cattle, distance to nearest house, $\%$ forest cover, index of deer abundance, and size of pasture). In addition, we examined whether the 5 pasture characteristics were different between pastures in which livestock were killed by wolves versus pastures without livestock depredation events. We obtained cattle numbers from interviews with producers. We determined the proximity of livestock to houses by measuring the distance between the center point of each livestock pasture and the nearest house. We took forest habitat (deciduous and coniferous) from the MDNR's land use-land cover map and we measured the percentage of forest cover within a 750-m radius of the center point of each pasture. We determined an index of deer abundance for each pasture by counting sets of deer tracks along gravel roads adjacent to each pasture. We assumed the number of deer-track sets was correlated with deer density. We measured the deer abundance index as the frequency of deer-track sets divided by the length of roads (deer-track sets $/ \mathrm{km}$ ). We surveyed deer tracks at 3 intervals during the nonwinter months and 2 days after severe rainstorms to wash away old track sets. We used only pastures within the 3 resident wolf pack home ranges for analysis (Fig. 1).

\section{Documenting Depredation Events}

In Minnesota, farmers have the option of either contacting a MDNR conservation officer or a government wolf-control specialist (United States Department of Agriculture-Wildlife

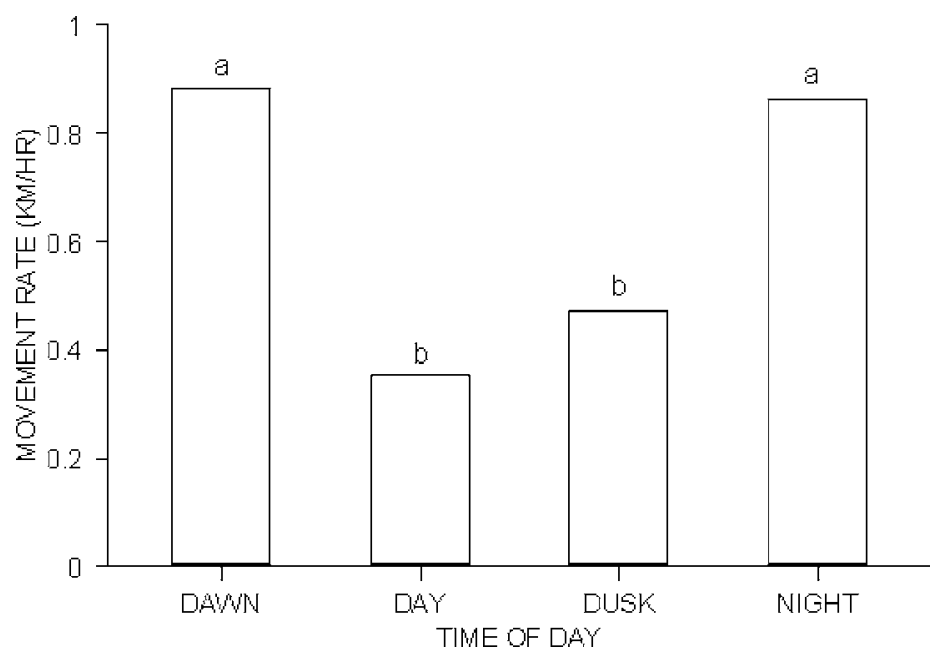

Figure 2. Movement rates of wolves during the nonwinter seasons of 1998 and 1999 at Agassiz, northwestern Minnesota, USA. Time periods were dawn ( $1 \mathrm{hr}$ before-2 $\mathrm{hr}$ after sunrise), day ( $2 \mathrm{hr}$ after sunrise- $1 \mathrm{hr}$ before sunset), dusk ( $1 \mathrm{hr}$ before $-2 \mathrm{hr}$ after sunset), and night ( $2 \mathrm{hr}$ after sunset $-1 \mathrm{hr}$ before sunrise). Time periods with different letters indicate a statistical difference.

Services) for verification on claims of potential wolf depredations on livestock (Fritts et al. 1992). We were provided with information on the estimated date of the depredation event, location, and livestock involved so that we could examine the relationship between wolf visitation and the timing of depredation events.

\section{Results}

We captured 23 wolves, including pups, between June 1997 and November 1999 and radiocollared 16 wolves in 3 packs. Nine of the 16 radioed wolves (56\%) died during the study (1997-1999), resulting in the turnover of 2 wolf packs. Of the 9 deaths we documented, 4 wolves were illegally killed by humans, 3 were killed during control actions following livestock depredations, and 2 died of mange. Early winter mean pack sizes for the 3 packs in 1998 and 1999 was 7.0 wolves \pm 3 SD (range 2-11 wolves).

\section{Home Range, Habitat Use, and Daily Activity Patterns}

Wolf home-range size ranged between $147-240 \mathrm{~km}^{2}$ during 1998-1999 and contained an average of 39\% agricultural lands. We analyzed habitat selection patterns for 3 wolf packs over 2 years from 4,945 telemetry locations. Habitat use for all time periods combined revealed that wolf packs exhibited no selection patterns for open, semi-open, or closed habitats $(F=0.25, \mathrm{df}=4$, $P=0.79)$. However, we found selection for certain habitat types when we analyzed habitat use for day and night locations separately. During the day, wolf packs selected semi-open and closed habitats significantly more than expected and open habitats less than expected (Table 1). In contrast, wolves selected open and closed habitats during nighttime significantly more than expected and semi-open habitats less than expected (Table 1).

We examined daily activity patterns from 178 24-hour radiotracking sessions on 7 wolves ( $2 \mathrm{M}, 5 \mathrm{~F})$. Activity patterns during the 4 diel periods differed significantly from each other $(H=$ 14.80, $P=0.02)$; night and dawn periods had significantly higher rates of movement than day and dusk periods (Fig. 2). 


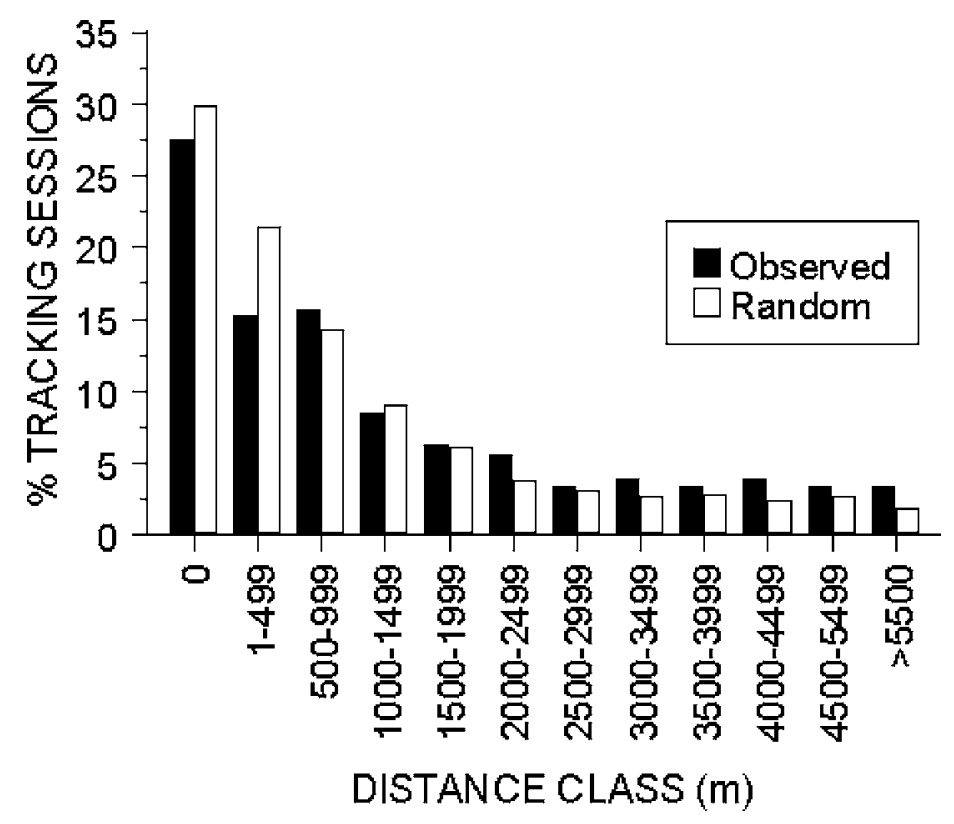

Figure 3. The percent of radiotracking sessions of wolves either passing through a livestock pasture (distance zero) or passing by a pasture at various distance classes for observed wolf movements and random simulated movements during 1998-1999, northwestern Minnesota, USA.

\section{Visitation Rates into Pastures}

A wolf visited a livestock pasture (with cattle) during $28 \%$ of the 178 24-hour tracking sessions (Fig. 3). Wolves passed within $1 \mathrm{~km}$ of a pasture during $58 \%$ of the sessions; $95 \%$ were $\leq 5 \mathrm{~km}$ from a pasture. From the simulated random-directional movements, $30 \%$ of the random movements passed through a pasture; $65 \%$ and $95 \%$ of random movements were within $\leq 1 \mathrm{~km}$ and $\leq 5 \mathrm{~km}$ of a pasture, respectively. We found no statistical difference $\left(\chi^{2}=5.17\right.$, $\mathrm{df}=11, P=0.92)$ between the frequency of distances between locations and pastures based on the random movements and observed wolf movements (Fig. 3). There were no differences among the biological seasons in wolf visitation rates into livestock pastures $(H=4.66, \mathrm{df}=2, P=0.099)$, but there was a significant difference in the visitation rates for the different time periods of the day $(H=8.077, \mathrm{df}=3, P=0.044)$. Pastures were visited more

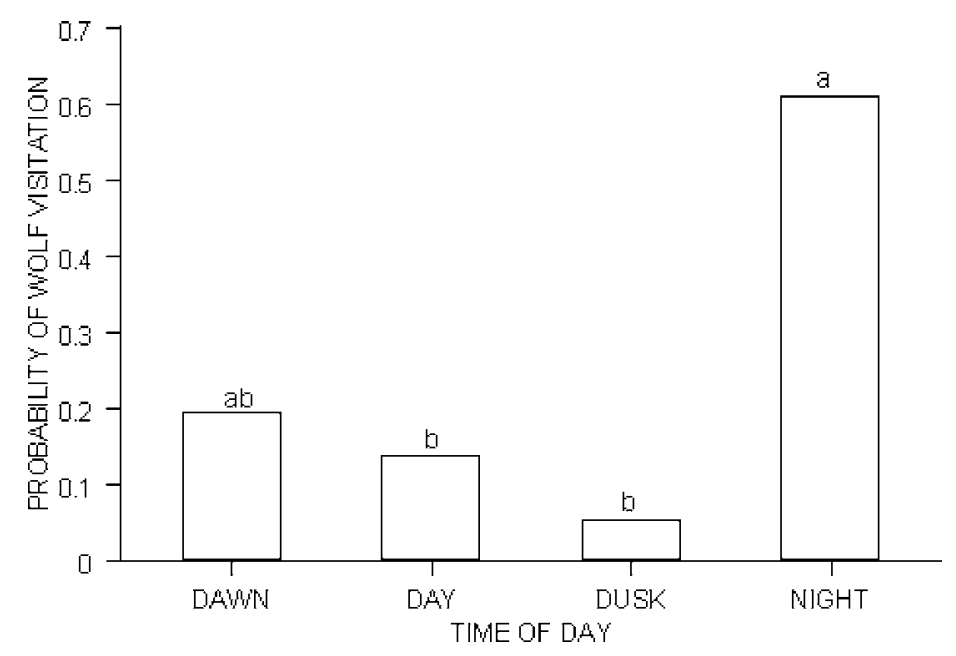

Figure 4. Probability of wolf packs visiting a pasture area during different time periods of the day during the nonwinter seasons, northwestern Minnesota, USA, 1998-1999. Time periods with different letters are statistically different.

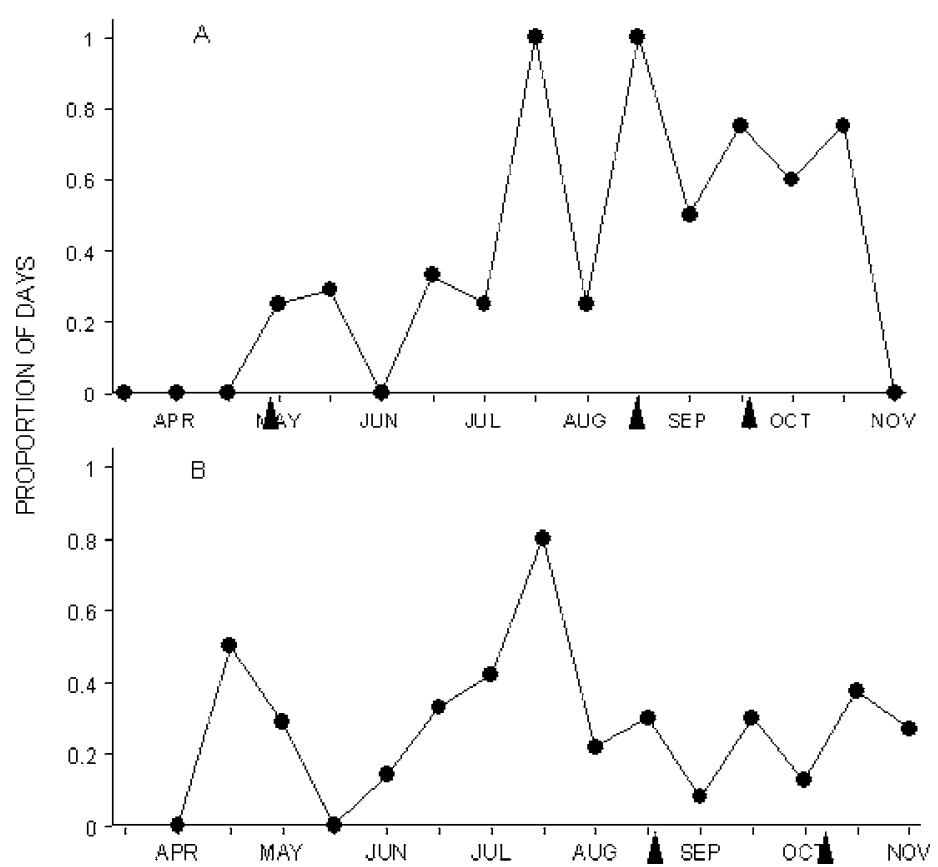

Figure 5. Proportion of days during 2-week intervals that a wolf pack visited a pasture area during a 24-hr time period for (A) 1998 and (B) 1999, northwestern Minnesota, USA. Arrows indicate dates of wolf depredation events on livestock.

often at night than day or dusk, but not greater than dawn (Fig. 4). In addition, high rates of wolf visitation into a pasture with cattle were not always associated with a livestock depredation event occurring (Fig. 5).

Pasture areas that were and were not visited during 1998 and 1999 did not show any differences in their pasture area characteristics (density of cattle, distance to nearest house, index of deer density, and size of pastures), except for the size of the pasture in 1998 (Table 2) with wolves visiting larger pastures than smaller pastures. Although sample size of pastures in which livestock were killed by wolves was limited in $1998(n=3)$ and $1999(n=2)$, we found wolves killed livestock in pastures containing more cattle, but only in 1998 (Table 3). No other pasture characteristics were significant between pastures with and without wolf depredations on livestock.

\section{Livestock Depredation Events}

From 1997-1999, there were 8 head of livestock officially reported as wolf depredation incidents in the agricultural lands within 6.4 $\mathrm{km}$ from Agassiz. The livestock confirmed to have been killed by wolves during our study consisted of 1 sheep, 1 cow with a debilitating hoof disease, 1 blind cow, and 5 calves. Four wolves were killed in the study area in response to these verified depredation complaints. Surveys of livestock producers indicated there were approximately 1,985 head of cattle living on agricultural lands within the study area.

\section{Discussion}

\section{Home Range, Habitat Selection, and Daily Activity Patterns}

Human disturbance in the form of agriculture was a predominant land use in our study area. Raising livestock was one of the most 
Table 2. A comparison of mean pasture area characteristics of 22 pastures that were and were not visited by wolves, northwestern Minnesota, USA, $1998-1999$.

\begin{tabular}{|c|c|c|c|c|c|c|c|c|c|}
\hline \multirow[b]{2}{*}{ Pasture characteristic } & \multirow[b]{2}{*}{ Pasture visited } & \multicolumn{4}{|c|}{1998} & \multicolumn{4}{|c|}{1999} \\
\hline & & $N$ & $\overline{\boldsymbol{x}}$ & $t$ & $\boldsymbol{P}$ & $N$ & $\overline{\boldsymbol{x}}$ & $t$ & $P$ \\
\hline \multirow[t]{2}{*}{ No. of cattle } & No & 14 & 86.8 & 0.344 & 0.73 & 13 & 92.7 & -0.224 & 0.82 \\
\hline & Yes & 8 & 96.2 & & & 9 & 86.7 & & \\
\hline \multirow[t]{2}{*}{ Distance to closest house (m) } & No & 14 & 443.4 & 1.245 & 0.23 & 13 & 502.8 & 0.383 & 0.71 \\
\hline & Yes & 8 & 694.6 & & & 9 & 580.9 & & \\
\hline \multirow[t]{2}{*}{$\%$ Forest cover } & No & 14 & 6.8 & 1.429 & 0.17 & 13 & 7.6 & 0.500 & 0.62 \\
\hline & Yes & 8 & 10.5 & & & 9 & 9.0 & & \\
\hline \multirow[t]{2}{*}{ Deer-track index } & No & 14 & 8.2 & 0.348 & 0.73 & 13 & 7.0 & -1.245 & 0.23 \\
\hline & Yes & 8 & 8.8 & & & 9 & 4.9 & & \\
\hline \multirow[t]{2}{*}{ Size of pasture $\left(\mathrm{km}^{2}\right)$} & No & 14 & 0.30 & 2.146 & 0.04 & 13 & 0.39 & 0.083 & 0.93 \\
\hline & Yes & 8 & 0.56 & & & 9 & 0.40 & & \\
\hline
\end{tabular}

important types of agriculture and the habitats associated with this practice were mostly open. Vast areas of open habitat in agricultural lands were a dangerous environment for wolves to travel through due to illegal poaching (Chavez 2002). However, agricultural lands were used by wolves. Furthermore, human disturbance did not appear to have a major influence on homerange size since the wolf home-range size was within the range of home-range sizes for other areas containing little or no agricultural lands in the Upper Midwest (e.g., Fritts and Mech 1981, Berg and Kuehn 1982, Fuller 1989). It has been hypothesized that wolf home-range sizes are influenced by prey density (Messier 1985, Fuller 1989), wolf density (Fritts and Mech 1981), and to a lesser extent by pack size (Peterson et al. 1984, Messier 1985). Ciucci et al. (1997) proposed other factors, such as the nature and dispersion of food resources, topography, and human disturbance, as also influencing wolf home-range size.

Wolves were possibly able to reduce the effect of human disturbance on their home-range use by patterning their habitat selection and daily activity to where and when they were least likely to encounter humans and, hence, be vulnerable to poaching. Wolves selected closed (forests) and semi-open (brushland and marshland) vegetation communities the most during daytime. In contrast, wolves selected open vegetation communities, such as agricultural lands and grasslands, and closed vegetation communities the most during nighttime. The different patterns of habitat selection between the 2 periods of the day meant that wolves were able to minimize threats from humans by using open habitats, such as agricultural lands, most often during nighttime, when humans were least able to shoot them. During daytime, wolves were usually difficult for humans to locate or notice since they were using closed habitats most often.

Due to our study design, we did not attempt to ascertain how much human disturbance affected these habitat selection patterns. Previous studies on wolves living adjacent to vast open farmlands in another area of northwestern Minnesota and Riding Mountain National Park, Manitoba, reported wolves did not cross large open spaces in farmlands (Carbyn 1980, Fritts et al. 1992). However, these studies may have missed recording wolf movements in farmlands at night, since they relied mostly on daytime aerial telemetry for locating wolves. Nonetheless, since wolves historically and presently occupy areas with vast amounts of open habitat, such as the Great Plains and Arctic regions, we presume wolves are inherently capable of utilizing areas with vast open habitat during daytime. The way in which they pattern their behavior is likely dependent on several factors, including threats from humans.

By being less active during daytime and being most active during night, wolves may be minimizing encounters with humans. Studies on wolves living in high-human-density areas in Europe reported nocturnal behavior by wolves was a strategy for avoiding humans (Vila et al. 1995, Ciucci et al. 1997). However, wolves living in low-human-density areas also were mostly nocturnal (Scott and Shackelton 1982, Groebner 1991), indicating other factors may be causing these patterns by wolves.

Theoretically, animals make decisions about their temporal and space-use patterns to maximize their efficiency of procuring resources while minimizing risks, and ultimately to enhance their fitness (Pulliam 1989). Wolves may have sought cover and

Table 3. A comparison of mean pasture characteristics of 22 pastures in which livestock were or were not killed by wolves, northwestern Minnesota, USA, $1998-1999$.

\begin{tabular}{|c|c|c|c|c|c|c|c|c|c|}
\hline \multirow[b]{2}{*}{ Pasture characteristic } & \multirow[b]{2}{*}{ Livestock killed } & \multicolumn{4}{|c|}{1998} & \multicolumn{4}{|c|}{1999} \\
\hline & & $N$ & $\bar{x}$ & $\boldsymbol{t}$ & $\boldsymbol{P}$ & $N$ & $\bar{x}$ & $t$ & $\boldsymbol{P}$ \\
\hline \multirow[t]{2}{*}{ No. of cattle } & No & 19 & 79.7 & 2.223 & 0.04 & 20 & 91.7 & 0.364 & 0.72 \\
\hline & Yes & 3 & 156.7 & & & 2 & 75.0 & & \\
\hline \multirow[t]{2}{*}{ Distance to closest house (m) } & No & 19 & 526.2 & 0.215 & 0.83 & 20 & 521.9 & -0.403 & 0.69 \\
\hline & Yes & 3 & 589.3 & & & 2 & 662.7 & & \\
\hline \multirow[t]{2}{*}{$\%$ Forest cover } & No & 19 & 7.9 & 0.523 & 0.61 & 20 & 8.1 & -0.321 & 0.75 \\
\hline & Yes & 3 & 9.9 & & & 2 & 9.5 & & \\
\hline \multirow[t]{2}{*}{ Deer-track index } & No & 19 & 8.6 & -0.429 & 0.67 & 20 & 6.0 & -0.617 & 0.54 \\
\hline & Yes & 3 & 7.5 & & & 2 & 7.8 & & \\
\hline \multirow[t]{2}{*}{ Size of pasture $\left(\mathrm{km}^{2}\right)$} & No & 19 & 0.39 & 0.178 & 0.86 & 20 & 0.38 & -1.119 & 0.28 \\
\hline & Yes & 3 & 0.43 & & & 2 & 0.62 & & \\
\hline
\end{tabular}


reduced their activity during daytime to minimize energetic costs associated with direct solar radiation (e.g., Demarchi and Bunnell 1995). Furthermore, the activity pattern and distribution of their prey also may influence wolf behavior. Wolves were possibly most active and selected open habitat most often during nighttime to synchronize their activity and habitat selection with the patterns of their main prey, deer and moose (Phillips et al. 1973, Kammermeyer and Marchinton 1977, Beier and McCullough 1990).

\section{Visitations into Pastures}

Despite the high frequency of wolf visits to pastures containing livestock, several lines of evidence suggest wolves were not traveling in or near pastures with the intent of killing cattle. First, there appeared to be no relationship between depredation events and the frequency of wolf visitation to pastures. Second, the lack of relationships between pasture characteristics and the frequency of wolf visitation or frequency of livestock depredations, indicates wolves were not attracted to livestock pastures because they were of little value to wolves. Lastly, the lack of a difference between the frequency of wolf visitation into and near pastures based on simulated random movements versus real movements further supports the notion that wolves were not attracted to pastures because of cattle and randomly passed through pastures on their way to other resources.

We believe wolves were motivated by other factors in the agricultural lands and were inadvertently passing through or near pastures. White-tailed deer were common in agricultural lands and were the wolves' main prey (Chavez and Gese 2005). Thus, the presence of deer likely was a strong motivation for wolves to travel in agricultural lands. Carrion from livestock possibly was another factor encouraging wolves to travel in agricultural lands. This was verified by some landowners reporting signs of wolves next to dead livestock, some of which were not removed from the pasture. We found a domestic pig carcass dump that was heavily used by radioed wolves during 1997 and 1998. When the farmer stopped dumping carcasses near his property the following year, the wolves rarely traveled to that area again.

In Minnesota, a study by Mech et al. (2000) reported that larger pastures, pastures with more cattle, and pastures farther from human dwellings distinguished farms with chronic wolf depredations on livestock from farms without wolf depredations. That study appeared to produce contrasting results to ours. However,

\section{Literature Cited}

Alldredge, J. R., and J. T. Ratti. 1986. Comparison of some statistical techniques for analysis of resource selection. Journal of Wildlife Management 50:157-165.

Alldredge, J. R., and J. T. Ratti. 1992. Further comparison of some statistical techniques for analysis of resource selection. Journal of Wildlife Management 56:1-9.

Barrett, M. W., J. W. Nolan, and L. D. Roy. 1982. Evaluation of a hand held net-gun to capture large mammals. Wildlife Society Bulletin 10:108-114.

Beier, P., and D. R. McCullough. 1990. Factors influencing white-tailed deer activity patterns and habitat use. Wildlife Monographs 109.

Bell, W. J. 1991. Searching behavior: the behavioral ecology of finding resources. First edition. Chapman and Hall, London, United Kingdom.

Berg, W. E., and S. Benson. 1999. Updated wolf population estimate for Minnesota, 1997-1998. Minnesota Department of Natural Resources, Grand Rapids, USA.

Berg, W. E., and D. W. Kuehn. 1982. Ecology of wolves in north-central their analysis was not comparable to ours, since they examined chronic wolf-depredation farms, implying that the wolves in their study developed a propensity to kill livestock. It appears wolves in our study area had not developed this tendency to kill livestock at a high rate but rarely kill livestock even when they passed through pastures. If they had killed livestock on all the nights they passed directly through a pasture, upwards of 50 head of stock would have been killed each year, rather than the 2 depredations reported annually.

\section{Management Implications}

Our study suggests that the potential risk wolves pose to cattle may be high. However, there was strong evidence indicating that the actual risk wolves pose to livestock was low as demonstrated by the low number of wolf depredations on livestock. Although the risk wolves pose to livestock may be low, it is still necessary to continue managing wolf-livestock conflicts. Losses to an individual producer could be substantial in these days of marginal profits. Wolf depredation events are volatile issues that can severely incense rural attitudes toward wolves (Chavez et al. 2005), a species already embroiled in controversy.

Management actions alleviating conflicts between humans and wolves will allow for the continued persistence of wolves in this agriculture-wildland matrix. Removal of depredating wolves, disposal of livestock carcasses, knowledge and practice of effective animal husbandry, and maintenance of adequate populations of native ungulates should be goals of management agencies involved with wolf conservation in the area.

\section{Acknowledgments}

Logistical and financial support provided by the United States Fish and Wildlife Service-Agassiz National Wildlife Refuge and the United States Department of Agriculture, Wildlife Services, National Wildlife Research Center, Logan Field Station at Utah State University. We thank M. Young, K. Frykmen, M. Hackett, C. Hill, E. Peacock, S. Naftal, A. Hendel, J. Sikich, S. Richter, S. Graham, M. Clark, R. Callan, E. Joyce, L. Schutte, J. Muntifering, and E. Bergman for field assistance; M. Anderson, G. Huschle, S. Wockenfuss, and D. Van Eps at Agassiz National Wildlife Refuge for logistical and technical support; and D. Blumstein, B. Gilbert, R. Krannich, and an anonymous reviewer for reviews of the manuscript.

Minnesota. Pages 4-11 in F. H. Harrington and P. C. Paquet, editors. Wolves of the world: perspectives of behavior, ecology, and conservation. Noyes, Park Ridge, New Jersey, USA.

Carbyn, L. N. 1980. Ecology and management of wolves in Riding Mountain National Park, Manitoba. Canadian Wildlife Service for Parks, Canadian Larger Mammal Systems Study Report 10, Edmonton, Alberta, Canada.

Carbyn, L. N. 1983. Wolf predation on elk in Riding Mountain National Park, Manitoba. Journal of Wildlife Management 47:963-976.

Chavez, A. S. 2002. Assessing the potential, actual, and perceived risk that gray wolves, Canis lupus, pose to livestock in northwestern Minnesota. Thesis, Utah State University, Logan, USA.

Chavez, A. S., and E. M. Gese. 2005. Food habits of wolves in relation to livestock depredations in northwestern Minnesota. American Midland Naturalist 154:253-263.

Chavez, A. S., E. M. Gese, and R. S. Krannich. 2005. Attitudes of rural 
landowners toward wolves in northwestern Minnesota. Wildlife Society Bulletin 33:517-527.

Ciucci, P., L. Boitani, F. Francisci, and G. Andreoli. 1997. Home range, activity and movements of a wolf pack in central Italy. Journal of Zoology, London 243:803-819.

Conover, W. J. 1999. Practical nonparametric statistics. Third edition. John Wiley and Sons, New York, New York, USA.

Demarchi, M. W., and F. L. Bunnell. 1995. Forest cover selection and activity of cow moose in summer. Acta Theriologica 40:23-36.

Fritts, S. H., and L. D. Mech. 1981. Dynamics, movements, and feeding ecology of a newly protected wolf population in northwestern Minnesota. Wildlife Monographs 80.

Fritts, S. H., W. J. Paul, L. D. Mech, and D. P. Scott. 1992. Trends and management of wolf-livestock conflicts in Minnesota. U.S. Fish and Wildlife Service Resource Publication 181, Washington, D.C., USA.

Fuller, T. K. 1989. Population dynamics of wolves in north-central Minnesota. Wildlife Monographs 105.

Gese, E. M., D. E. Andersen, and O. J. Rongstad. 1990. Determining homerange size of resident coyotes from point and sequential locations. Journal of Wildlife Management 54:501-506.

Gese, E. M., and L. D. Mech. 1991. Dispersal of wolves (Canis lupus) in northeastern Minnesota, 1969-1989. Canadian Journal of Zoology 69: 2946-2955.

Groebner, D. J. 1991. Summer movement rates of a pair of northeastern Minnesota timber wolves. Thesis, Northern Michigan University, Marquette, USA.

Hooge, P. N., and B. Eichenlaub. 1997. Animal movement extension to Arcview. Version 1.1. U.S. Geological Survey, Alaska Biological Science Center, Anchorage, USA.

Kammermeyer, K. E., and R. L. Marchinton. 1977. Seasonal change in circadian activity of radiomonitored deer. Journal of Wildlife Management 41: 315-317.

Kreeger, T. J. 1996. Handbook of chemical immobilization. International Wildlife Veterinary Services, Laramie, Wyoming, USA.

Kuehn, W., T. K. Fuller, L. D. Mech, W. J. Paul, S. H. Fritts, and W. E. Berg. 1986. Trap-related injuries to gray wolves in Minnesota. Journal of Wildlife Management 50:90-91.

Mech, L. D. 1966. The wolves of Isle Royale. U.S. National Park Service, Fauna Series 7, Washington, D.C., USA.

Mech, L. D. 1970. The wolf: the ecology and behavior of an endangered species. Natural History, Garden City, New York, USA.

Mech, L. D., E. K. Harper, T. J. Meier, and W. J. Paul. 2000. Assessing factors that may predispose Minnesota farms to wolf depredations on cattle. Wildlife Society Bulletin 28:623-629.

Mech, L. D., and P. D. Karns. 1977. Role of the wolf in a deer decline in the Superior National Forest. U.S. Forest Service Research Paper NC-148, St. Paul, Minnesota, USA.
Messier, F. 1985. Social organization, spatial distribution, and population density of wolves in relation to moose density. Canadian Journal of Zoology 63:1068-1077.

Mohr, C. O. 1947. Table of equivalent populations of North America small mammals. American Midland Naturalist 37:223-249.

Otis, D. L., and G. C. White. 1999. Autocorrelation of location estimates and the analysis of radiotracking data. Journal of Wildlife Management 63:10391044.

Peterson, R. O., J. D. Woolington, and T. N. Bailey. 1984. Wolves of the Kenai Peninsula, Alaska. Wildlife Monographs 88.

Phillips, R. L., W. E. Berg, and D. B. Siniff. 1973. Moose movement patterns and range use in northwestern Minnesota. Journal of Wildlife Management 37:266-278.

Pulliam, H. R. 1989. Individual behavior and the procurement of essential resources. Pages 25-38 in J. Roughgarden, R. M. May, and S. A. Levin, editors. Perspectives in ecological theory. Princeton University, New Jersey, USA.

Sahr, D. P., and F. F. Knowlton. 2000. Evaluation of tranquilizer trap devices (TTDs) for foothold traps used to capture gray wolves. Wildlife Society Bulletin 28:597-605.

Scott, B. M. V., and D. M. Shackleton. 1982. A preliminary study of the social organization of the Vancouver Island Wolf: (Canis lupus crassodon; Hall, 1932). Pages 12-24 in F. H. Harrington and P. C. Paquet, editors. Wolves of the world: perspectives of behavior, ecology, and conservation. Noyes, Park Ridge, New Jersey, USA.

Southwood, T. R. E. 1966. Ecological methods with particular reference to the study of insect populations. Methuen, London, United Kingdom.

Swihart, R. K., and N. A. Slade. 1985. Testing for independence of observations in animal movements. Ecology 66:1176-1184.

United States Fish and Wildlife Service. 1978. Recovery plan for the eastern timber wolf. Eastern Timber Wolf Recovery Team, U.S. Government Printing Office, Washington, D.C., USA.

Van Ballenberghe, V., A. W. Erickson, and D. Byman. 1975. Ecology of the timber wolf in northeastern Minnesota. Wildlife Monographs 43.

Vila, C., V. Urios, and J. Castroviejo. 1995. Observations of the daily activity patterns in the Iberian wolf. Pages 335-340 in L. N. Carbyn, S. H. Fritts, and D. R. Seip, editors. Ecology and conservation of wolves in a changing world. Canadian Circumpolar Institute, Occasional Publication 35, University of Alberta, Edmonton, Canada.

White, G. C., and R. A. Garrott. 1990. Analysis of wildlife radiotracking data. Academic, New York, New York, USA.

Young, S. P., and E. A. Goldman. 1944. The wolves of North America. Dover, New York, New York, USA.

Zar, J. H. 1996. Biostatistical analysis. Third edition. Prentice-Hall, Englewood Cliffs, New Jersey, USA.

Associate Editor: Lanham. 